Fox, C., Buchanan-Barrow, E. \& Barrett, M. (2010). Children's conceptions of mental illness: A naïve theory approach. British Journal of Developmental Psychology, 28, 603-625.

\title{
Children's Conceptions of Mental Illness: A Naïve Theory Approach
}

Claudine Fox ${ }^{1}$, Eithne Buchanan-Barrow ${ }^{2}$ and Martyn Barrett ${ }^{2}$

${ }^{1}$ Department of Psychology, Newman University College, Birmingham, UK

${ }^{2}$ Department of Psychology, University of Surrey, Guildford, UK 


\title{
Children's Conceptions of Mental Illness: A Naïve Theory Approach
}

\begin{abstract}
This paper reports two studies that investigated children's conceptions of mental illness using a naïve theory approach (Wellman \& Gelman, 1992, 1998), drawing upon a conceptual framework for analyzing illness representations which distinguishes between the identity, causes, consequences, curability and timeline of an illness (Leventhal, Meyer, \& Nerenz, 1980; Leventhal, Nerenz, \& Steele, 1984). The studies utilised semi-structured interviewing and card selection tasks to assess 6- to 11-year-old children's conceptions of the causes and consequences (Study 1) and the curability and timeline (Study 2) of different mental and physical illnesses/ailments. The studies revealed that, at all ages, the children held coherent causalexplanatory ideas about the causes, consequences, curability and timeline of both mental and physical illnesses/ailments. However, while younger children tended to rely on their knowledge of common physical illnesses when thinking about mental illnesses, providing contagion and contamination explanations of cause, older children demonstrated differences in their thinking about mental and physical illnesses. No substantial gender differences were found in the children's thinking. It is argued that children hold coherent conceptions of mental illness at all ages, but that mental illness only emerges as an ontologically distinct conceptual domain by the end of middle childhood.
\end{abstract}

Keywords: illness representations, mental illness, physical illness, cognitive development, naïve theory. 


\section{Children's Conceptions of Mental Illness: A Naïve Theory Approach}

There has been relatively little empirical work that has specifically investigated children's conceptions of mental illness in comparison to the large body of work that has investigated adults' conceptions. Understanding children's thinking about mental health problems may not only aid in communication with children in providing age-appropriate explanations of mental illness, but also inform interventions into stigma reduction.

Research into children's mental illness concepts indicates that children often incorrectly attribute behaviours such as suicidal behaviour, hostility and aggression, and self-abusive behaviours to the mentally ill (de Rosa, 1987; Poster, Betz, Mckenna, \& Mossar, 1986). Studies have also found developmental trends in children's thinking (e.g., Conant \& Budoff, 1983; Dollinger, Thelen, \& Walsh, 1980; Royal \& Roberts, 1987; Spitzer \& Cameron, 1995; Weiss, 1985). This research, which has investigated children from age 6 to 18 , has revealed that younger children tend to confuse mental and physical illness, and are less able to describe specific characteristics of mental illness, whereas older children are more able to conceptualise mental illness as a disturbance of thought and emotion, and have a broader understanding of treatment (Wahl, 2002).

It has also been found that children at even the earliest ages studied, 6 and 7 years, have negative attitudes towards the mentally ill. They perceive the mentally ill as less attractive than individuals with other disabilities, want greater social distance from individuals with mental health problems, and rate such individuals less positively (e.g., Poster et al., 1986; Weiss, 1986; 1994; Wilkins \& Velicer, 1980). Furthermore, most studies have found that children's attitudes towards the mentally ill become more negative with age (Royal \& Roberts, 1987; Weiss, 1986, 1994). Findings are less clear in terms of gender differences. While some studies report differences between girls' and boys' conceptions of mental illness, with girls tending to normalise the behaviour (Marsden \& Kalter, 1976), and showing greater compassion and social acceptance towards the mentally ill compared to boys (Ross \& Ashok, 1983), other studies have failed to find any gender differences in understanding or attitudes (e.g., Coie \& Pennington, 1976; Novak, 1974).

Much of the existing research with children (e.g., Ross \& Ashok, 1983; Weiss, 1986, 1994), however, has neglected to investigate either the linguistic terms which children themselves use spontaneously to refer to mental illness, or children's comprehension of the diverse range of linguistic terms (e.g., 'mentally ill', 'mental disorder', 'emotionally disturbed', etc.) which have been employed in different studies to investigate children's understanding of, and attitudes towards, mental illness. This raises questions not only about the comparability of findings across studies, but also about the validity of the findings obtained with terms that may not have been within children's own receptive or productive vocabularies. Furthermore, it raises issues around communication with children regarding mental illness, in terms of the use of age-appropriate explanations of mental health problems.

While there has been comparatively little research into children's thinking about mental illness, there has been continued research into children's understanding of physical illness (e.g., Bibace \& Walsh, 1980; Buchanan-Barrow, Bati, \& Barrett, 2003, 2004; Hergenrather \& Rabinowitz, 1991; Inagaki, 1997; Kalish, 1997; Perrin \& Gerrity, 1981; Siegal, 1988; Siegal \& Peterson, 1999). Among this body of research, some studies (e.g., Goldman, Whithney-Saltiel, Granger, \& Robin, 1991; Paterson, Moss-Morris, \& Butler, 1999) have utilised an analytic framework drawn from the study of adults' understanding of physical illnesses. This framework, 
which was originally developed by Leventhal and colleagues (Leventhal et al., 1980, 1984), draws conceptual distinctions between five components of adults' cognitive representations of illnesses: 1) identity: knowledge of the label and of the symptomatic properties that are associated with an illness; 2) cause: beliefs about the factors which bring about or trigger the illness; 3 ) timeline: beliefs about the temporal duration of the illness course and whether the illness is acute or chronic; 4) consequences: beliefs about the short-term or long-term effects or outcomes which occur during or after the illness; and 5) curability: beliefs about whether or not, and how, an individual can recover from the illness. All five components have been found to characterise adults' illness representations (Lau \& Hartman, 1983; Leventhal et al., 1980, 1984).

Studies that have utilised this framework for studying children's thinking about physical illness have found it useful. For example, Goldman et al. (1991) found that children aged 4- to 6years did understand a common illness (cold/fever) in terms of the five components. Similarly, Paterson et al. (1999) examined the concepts of colds and asthma in 7- to 14-year-olds with and without asthma. Differences were found in the children's understandings of the various illness components, whereby children with asthma showed greater knowledge of the causes, timeline and the control/curability of asthma than children without asthma. This model of illness

representations has not yet been employed to explore children's thinking about mental illness, and given its usefulness in studying children's understanding of physical illness, the two studies reported in the present paper adopted Leventhal's framework to study children's understanding of mental rather than physical illnesses.

In addition, the design of the present research was informed by the naïve theory approach to children's cognitive development (Wellman, 1990; Wellman \& Gelman, 1992, 1998). This approach postulates that children's understanding develops through the construction of naïve or intuitive theories, which themselves are subject to change as a result of the acquisition of new evidence or information, and so may be subsequently refined and reformulated during the course of development into more specific and/or qualitatively different theories. Crucially, these naïve theories enable the child to interpret, explain and make predictions about the phenomena falling within a particular domain, and are based around the child's construction of ontological distinctions, patterns of coherence across phenomena, and causal-explanatory frameworks (Wellman, 1990). That is to say, this approach proposes that children recognise that knowledge domains can differ fundamentally due to the fact that they contain very different types of conceptual content relating to qualitatively different types of entities in the world; in other words, it proposes that children have an understanding of basic ontological distinctions. This approach also proposes that children's beliefs about the phenomena which fall within a particular domain are rational and cohere into connected networks of reasoning, and that children utilise distinctive causal-explanatory principles when reasoning and making predictions about these phenomena. Thus, the child is viewed as a naïve theorist, constructing, elaborating and sometimes revising theories that are specialised for explaining the qualitatively different types of phenomena which occur within different conceptual domains.

In the field of children's understanding of physical illness, and consistent with the naïve theory argument, it has been found that children do indeed construct coherent causal-explanatory theories about physical illnesses, with these theories being influenced by the specific knowledge which children acquire (Sigelman, Maddock, Epstein, \& Carpenter, 1993). Developmental differences in children's causal-explanatory theories of physical illness have also been found, with older children demonstrating more accurate and differentiated reasoning (e.g., Hergenrather \& Rabinowitz, 1991). However, while this body of research supports a naïve theory interpretation of 
children's understanding of physical illness, there have been no investigations to date of children's conceptions of mental illness utilising this theoretical perspective on children's cognitive development. For this reason, the present studies were designed to apply the naïve theory perspective specifically to children's understanding of mental illness.

Thus, first, the present research aimed to make a theoretical contribution to the field, through its novel use of the naïve theory perspective to investigate children's conceptions of mental illness, focusing in particular on their conceptions of the illness representation components identified by Leventhal et al. (1980, 1984). Second, the research aimed to address methodological problems with existing studies into children's conceptions of mental illness in relation to linguistic terminology and unassisted verbal reporting. In order to do so, a preceding focus group study was carried out, to establish a reliable comprehensible vocabulary regarding mental illness for children aged between 5 and 11 years. This generated appropriate linguistic terminology, vignettes and response categories to utilise in the main studies.

Thirty six children took part in six focus groups; two focus groups for each age group were conducted (5- to 7-year-olds; 8 - to 9-year-olds; 10- to 11-year-olds). Three of the focus groups explored children's understanding of terms such as 'crazy', 'mad' and 'mentally ill', including specific diagnostic labels such as 'depression', 'dementia' and 'anorexia', while the other three presented children with vignettes describing symptoms of various specific mental illnesses. Discussions were broadly structured around the Leventhal five-component model: identity, cause, consequence, curability and timeline. Children were encouraged to discuss freely, and children of all ages contributed to the discussions.

Findings suggested that it would maximise children's performance in the main studies if they were presented with a combination of both diagnostic labels and vignettes describing specific behavioural symptoms of mental illnesses (rather than using general terms relating to individuals with mental health problems, or diagnostic labels alone). Furthermore, it was found that the vignettes presented to children in the focus group study were appropriate to utilise in their current form, even for the youngest children. The discussions also aided development of the card selection tasks incorporated into the semi-structured interviews planned for the main studies, which aimed to minimise problems associated with unassisted verbal reporting. In the main studies, children were asked to select their responses to questions from a series of cards that provided a wide range of possible responses. The response categories and the particular words which were written on the cards were generated directly from the children's responses to the vignettes and questions in the focus group study. This ensured that the words on the cards, and hence the children's responses, utilised linguistic terminology that was appropriate for children of the age range being tested. Full details of these preliminary focus group studies are reported in Fox (2005).

Two separate main studies were conducted, as it was judged that examining all the different components together within a single study might overload the children's processing capacities, particularly the younger children's. In addition, between them, the two studies aimed to examine: 1) children's conceptions of ontological distinctions, by investigating whether they differentiated between mental and physical illnesses/ailments as two separate domains; 2) the coherence of children's thinking about mental and physical illnesses/ailments; 3) children's ability to construct causal explanations of mental and physical illnesses/ailments.

Children's thinking about the causes and consequences of illnesses were investigated in Study 1, while their thinking about the curability and timeline of illnesses were investigated in Study 2. Their thinking about the identity of illnesses was not assessed as such, as the 
methodology required information about the labels and the symptomatic properties of different illnesses to be presented to the children by the experimenter. Thus, all children were provided with exactly the same clinically accurate information about each of the illnesses before they were questioned concerning causes, consequences, curability and timeline.

Based on previous studies, it was expected that, across this age range, the children would show developmental differences in their conceptions of both mental illness (Conant \& Budoff, 1983; Dollinger et al., 1980; Royal \& Roberts, 1987; Spitzer \& Cameron, 1995; Weiss, 1985) and physical illness/ailment (Hergenrather \& Rabinowitz, 1991; Inagaki, 1997; Kalish, 1997; Perrin \& Gerrity, 1981; Siegal, 1988; Siegal \& Peterson, 1999). Associations with gender were also investigated to try and clarify the mixed findings in the existing literature (cf. Coie \& Pennington, 1976; Marsden \& Kalter, 1976; Novak, 1974; Ross \& Ashok, 1983). 
Study 1: Causes and Consequences

\begin{abstract}
Method
Design

The study employed a 3 (age) x 2 (gender) x 6 (illness) mixed design, with independent groups on the first two factors and repeated measures on the final factor.
\end{abstract}

\title{
Participants
}

Children were recruited from three primary schools in Warwickshire, England. The study was conducted in accordance with the British Psychological Society's ethical principles for conducting research with human participants and the requirements of the University Ethics Committee of the University of Surrey. Informed consent for the children to take part in the study was given either by parents or by the headteacher acting in loco parentis. In addition, before commencing each interview, the child was asked whether he or she wanted to take part in the study and was given the option of withdrawing at any time. The researcher was sensitive to whether children appeared uncomfortable with participation; however, there were no children for whom consent had been obtained who subsequently opted out. Class teachers were asked to select the specific children to participate such that children with a range of academic abilities would take part in the study.

A total number of 122 children participated, with roughly equal numbers being recruited from each school. Children were divided into three groups: a 'young' group, which comprised children from School Year 2 (6- to 7-year-olds; 21 girls and 19 boys; mean age = 6.78; $\mathrm{SD}=0.42$ ); a 'middle' group of children from School Year 4 (8- to 9-year-olds; 20 girls and 20 boys; mean age $=8.78$; $\mathrm{SD}=0.42$ ); and an 'old' group of children from School Year 6 (10- to 11-year-olds; 21 girls and 21 boys; mean age $=10.83$; $\mathrm{SD}=0.38$ ).

\section{Materials}

Materials consisted of two parts. The first part comprised a vignette describing a principal character diagnosed with a mental illness (depression, anorexia nervosa, dementia) or a physical illness/ailment (chicken pox, broken arm, common cold). As a previous study has shown little or no prior experience of mental illness in children of this age group (Fox, 2005), the identity component of Leventhal's illness framework was explicitly given to the children as part of the vignettes. This allowed all of the children to be provided with identical and accurate information about the name and the symptoms of the different mental and physical illnesses. The second part of the materials consisted of the response cards, which were used in the card selection tasks, in which the children were questioned about the causes and consequences of each illness.

The choice of the mental illness diagnoses was dictated by the mental health problems focused upon by the Royal College of Psychiatrists' Stigma Campaign (1998-2003) and also by the need to control the age and gender of the principal characters in the vignettes. A greater number of females suffer from depression, anorexia nervosa and dementia (Alzheimer's type) than males (American Psychiatric Association, 1995). As these are also all conditions that are found in adults, it was decided to use an adult female character in all six vignettes. The symptoms for the mental illnesses in the vignettes were taken from the DSM IV (American Psychiatric Association, 1995). Physical illness/ailment diagnoses were chosen on the grounds that they were common ailments, and symptoms were drafted with the assistance of a qualified medical practitioner. The six vignettes are shown in Appendix 1. 
With reference to the response cards, the sets of responses which were presented to the children, were generated directly from the responses that had been produced by the children in the preceding focus group study. Thus, the children were presented with a range of response options that had been generated by other children of a similar age range (in which the causes and consequences had been found to fall into the categories of psychological, physical/medical, contagion/contamination and immanent justice). Children received a total number of 12 different response cards (six causes and six consequences). These are shown in Appendix 2. Cards each measured $12 \mathrm{~cm}$. in length and $6 \mathrm{~cm}$. in width. Words contained on the cards were typed in capital letters in a clear bold black font.

\section{Procedure}

The response cards were shuffled by the researcher prior to the commencement of each interview, so that each child was presented with a new randomly ordered set of cards, to control for order effects and any possible response biases. The order in which the mental and physical illness/ailment diagnoses were presented to each child was also randomised. Children were interviewed individually. Each child was informed that the researcher would tell them a story about some people with different sorts of illnesses, and that they would then be asked some questions about the people in the stories using cards, and they would be asked to choose one of the cards. Children were also assured that their responses would be anonymous, and they were told that they should choose whichever cards they felt to be right.

Children were then read a vignette describing an adult female diagnosed with the first mental or physical illness/ailment. Following the vignette, children were presented with a series of cards inquiring about the most likely cause and consequence of the illness/ailment presented in the vignette. Children were asked about each of the components separately. For each component, the relevant set of cards was laid out on the table simultaneously, and all of the cards were read aloud to make sure that the child understood what was written on them. Once the experimenter was sure that this was the case, the child was then asked to choose the most likely cause or consequence of the mental or physical illness/ailment in question. Children were presented with causes and consequences cards in a counterbalanced order. The chosen card was recorded. Components were inquired about using the following questions: Causes: 'How did this person get......... ?'; Consequences: 'What will happen to this person because they have.........?'. This procedure was repeated for each of the six illness diagnoses in turn. All answers were documented on a recording sheet. The interviewer was alert to possible weaknesses in the children's reading skills, giving assistance and double-checking each chosen response with the child wherever necessary.

\section{Results}

Children's responses were recorded as frequencies which, for each illness individually, were analysed using a 3 (age group) x 2 (gender) x 6 (response) hi log linear analysis, in order to ascertain whether there were any significant associations between responses and either age or gender. Due to the low frequencies in some of the cells, these analyses are conservative (Tabachnik \& Fidell, 2006).

\section{Children's ontological distinctions}

Children's responses to causes associated with age group. Significant associations between children's responses and their age group were found for depression $\left(\left({ }^{2}(8)=36.09, p<\right.\right.$ $0.01)$, anorexia nervosa $\left(\left({ }^{2}(8)=17.17, p<0.05\right)\right.$ and dementia $\left(\left({ }^{2}(8)=57.85, p<0.01\right)\right.$ (see 
Table 1) but not for chicken pox, cold and broken arm. Post hoc chi-squared analyses (see Table 1) showed that for depression, young children were more likely to choose 'she caught it from someone' compared to middle and old children, who were more likely to choose 'it's to do with how she thinks and feels' than young children. For anorexia nervosa, old children were more likely to choose 'it's to do with how she thinks and feels' than middle and young children. For dementia, young children were more likely to choose 'she caught it' compared to middle and old children, who were more likely to choose 'something is wrong with her brain' compared to young children. For chicken pox and common cold, all children tended to choose 'she caught it', and for broken arm, 'she fell off her bike'.

Children's responses to consequences associated with age group. Significant associations between children's responses and their age group were found for depression $\left(\left({ }^{2}(10)=34.40, p<\right.\right.$ $0.01)$, anorexia nervosa $\left(\left({ }^{2}(10)=31.59, p<0.01\right)\right.$ and dementia $\left(\left({ }^{2}(10)=34.97, p<0.01\right)\right.$ (see Table 2) but not for the physical illness/ailment diagnoses. Post hoc analyses revealed that, for depression, middle and old children were more likely to choose 'help and support from relatives' compared to young children, while the young children were more likely to choose 'stay at home' than old children. For anorexia nervosa, old children were more likely to choose 'have therapy' compared to young children, and for dementia, young children were more likely to choose 'see a doctor' compared to middle and old children, who were more likely to choose 'have therapy' than young children. For chicken pox and common cold, the majority of children chose 'see a doctor' and 'stay at home' as consequences, and for broken arm children tended to choose 'see a doctor' and 'have an operation'.

\section{The coherence of children's causal-explanatory frameworks}

In order to examine the coherence of the causal-explanatory frameworks (i.e., the causeconsequence links) which underlay the children's responses, and to ascertain the frequencies of the various 'types' (i.e., specific pairs of particular causes-consequences), the data were subjected to a configural frequency analysis (CFA). CFA is a non-parametric, multivariate analysis of association. It identifies patterns of responses that are either over-represented (types) or underrepresented (anti-types), based on a null hypothesis that the patterns are normally and randomly distributed (von-Eye, 1990). Each cause and consequence card was allocated a number, giving rise to 36 possible response patterns (profiles) for each mental and physical illness/ailment. Each child was allocated a response pattern based on their choice of cards for each mental and physical illness/ailment. For example, a child responding with 'she ate something bad' (cause) and 'she will need to see a doctor' (consequences) would be allocated a response pattern of ' 2,1 '.

A number of types, which occurred significantly more frequently than would be expected by chance, were identified. More profiles were obtained for the mental illnesses than the physical illness/ailment diagnoses. Overall, the different profiles obtained for each mental and physical illness/ailment highlighted commonality in the causes but variation in the consequences chosen (see Table 3 for the profiles (types) identified for each of the mental and physical illness/ailment diagnoses; the first number in the 'profile' column denotes the cause and the second the consequence). A hi log linear analysis showed a significant association between the children's response patterns and age for anorexia nervosa $\left(\left({ }^{2}(10)=23.67, p<0.01\right)\right.$ and dementia $\left(\left({ }^{2}(8)=\right.\right.$ $53.98, p<0.01)$. For anorexia nervosa, old children were more likely to choose profile 4,6 (cause: it's to do with how she thinks and feels, consequence: she will need to have therapy) than young and middle children. For dementia, younger children were more likely to choose profiles 
1,1 (cause: she caught it, consequence: see a doctor) and 5,1 (cause: something is wrong with her brain, consequence: see a doctor), and older children were more likely to choose profiles 5,3 (cause: something is wrong with her brain, consequence: she will need to have an operation), 5,5 (cause: something is wrong with her brain, consequence: she will need help and support) and 5,6 (cause: something is wrong with her brain, consequence: she will need to have therapy).

\title{
Children's responses associated with gender
}

The hi log linear analyses revealed very few significant associations between the children's responses and their gender. However, significant associations between children's responses and gender were found for the consequences of depression $\left(\left({ }^{2}(5)=16.89, p<0.01\right)\right.$, with boys being more likely to choose 'stay at home' than girls (35\% vs. $24 \%$ respectively; $z(1)=$ $2.35, p<0.01)$, who were more likely to choose 'she will need help and support from her relatives' than boys ( $74 \%$ vs. $52 \%$ respectively; $(2(1)=3.66, p<0.1)$. It is noteworthy there were no significant three-way associations between response, gender and age in any of the hi log linear analyses.

\section{Discussion}

The findings of Study 1 suggest that between the ages of 6 and 11, there is little change in children's conceptions of the causes and consequences of broken arms, chicken pox and colds. Age differences in their responses to depression, anorexia and dementia, however, suggest that their conceptions of mental illness do change during these years. The children exhibited coherence in the particular cause-consequence pairings that they produced, and while the pairings about the mental illnesses became factually more accurate with age, even the youngest children did not generate random pairings of causes and consequences, as shown by the results of the CFA. It should also be noted that the younger children appeared to rely on what they already knew about common physical illnesses/ailments in order to reason about the mental illnesses (see the General Discussion for a more detailed discussion of this point).

Study 2: Curability and Timeline

The second study was designed to explore the children's understanding of the remaining two components of the Leventhal model, namely the curability and timelines of different illnesses, using the same methodological approach as in Study 1 .

\author{
Method \\ Design \\ This study also involved a 3 (age) x 2 (gender) x 6 (illness) mixed design, with \\ independent groups on the first two factors and repeated measures on the third factor.
}

\section{Participants}

Children were recruited from three primary schools in Warwickshire, England, which were different from those in Study 1. Recruitment of the children was carried out in the same way as in Study 1. Overall, 118 children took part, with roughly equal numbers of children from each school. Children were divided into the three same groups as Study 1; a 'young' group of children from School Year 2 (6- to 7-year-olds; 19 girls and 20 boys; mean age $=6.38$; SD =0.49), a 'middle' group of children from School Year 4 (8- to 9-year-olds; 21 girls and 20 boys; mean age $=8.41 ; \mathrm{SD}=0.50)$ and an 'old' group of children from School Year 6 (10- to 11-year-olds; 18 
girls and 20 boys; mean age $=10.45 ; \mathrm{SD}=0.50$ ).

\section{Materials}

Children were presented with a vignette describing a principal character diagnosed with a mental or physical illness/ailment, followed by a card selection task. The mental illness diagnoses presented to the children were identical to those used in Study 1. However, to explore whether children were reasoning about the mental and physical illnesses/ailments based on an 'acutechronic' criterion, for the physical illness/ailment conditions the children were presented with asthma (a chronic illness) instead of common cold (an acute illness), in order to offer a contrast with chicken pox and broken arm (acute illnesses/ailments). The causes of the mental and physical illnesses/ailments were also incorporated into the vignettes in order to hold the cause constant for each individual illness while the children reasoned about its consequences, curability and timeline. (See Appendix 1 for details of the vignettes.)

The second part of the materials consisted of the cards which were used in the card selection tasks (see Appendix 2). To simplify the consequences task for the children, the number of consequence cards was reduced from six to four. The four retained cards still represented a range of different types of responses (medicalised, psychological and physical). However, 'she will have an operation' was not retained, as one would first need to go and see a doctor in order to have an operation, and an operation may therefore be viewed as a more serious consequence of an illness. The immanent justice consequence, 'she will have to be nice to her friend', was also not retained, as this card had only been chosen by a minority of children in Study 1, almost entirely as a consequence for depression.

Curability was investigated with 'yes' and 'no' cards. With respect to timeline, previous work has shown that even young children (4- and 5-year-olds) recognise that there is a temporal gap before recovery from an illness (Raman \& Gelman, 2007). Timeline cards for the present study were generated directly from children's responses in relation to timeline in the focus group study. The timeline categories were divided into: a relatively short-term recovery time of 'less than 1 month', a middle-term recovery time of ' 1 month to 6 months' and more long-term recovery times of ' 6 months to 1 year' and 'more than 1 year'. There were therefore 10 different response cards (four consequences, two curability, four timeline). These were of the same size and contained the same kind of writing as had been used in the first study.

\section{Procedure}

The individual interviews were carried out in the same way as in Study 1; thus, each child was interviewed individually and presented with new randomly ordered sets of cards. Components were inquired about using the following questions: Consequences: 'What will happen to this person because they have.........?'; Curability: 'Do you think this person with......... can get better?' ; Timeline: 'How long do you think it will take the person with......... to get better?'. This process was repeated for each of the mental and physical illness/ailment diagnoses in turn. Children were questioned about these components in a random order. Where children were questioned about curability before timeline, and children responded 'no', they were not then asked about timeline as this would have violated normal conversational pragmatics. 
Once again, data were analysed using hi log linear analyses in order to ascertain whether there were any significant associations between responses and either age group or gender.

\section{Children's ontological distinctions}

Children's responses to consequences associated with age group. Significant associations between children's responses and age group were found for depression $\left(\left({ }^{2}(6)=22.36, p<0.01\right)\right.$ and anorexia nervosa $((2)=14.84, p<0.05)$, but not for dementia or the physical illnesses/ailments (see Table 4). The significant results were followed up using post hoc chisquared tests. These revealed that for depression, young children were more likely to choose 'see a doctor' compared to old children, who were more likely to choose 'have therapy' compared to children from both the young and middle age groups. For anorexia nervosa, old children were more likely to choose 'have therapy' compared to young children. Although not significant, frequencies for dementia indicated that younger children tended to choose 'see a doctor', while older children tended to choose 'help and support'. For the physical illnesses/ailments, none of the hi log linear analyses was significant, with the children tending to choose 'see a doctor' irrespective of age group.

Children's responses to curability/timeline associated with age group. For the purpose of analysis, curability and timeline were pooled by incorporating the curability category 'no' as a 'never' timeline category when coding the data, yielding five response categories in total. Significant associations with children's responses and their age group were found for depression $\left(\left({ }^{2}(6)=31.95, p<0.01\right)\right.$, anorexia nervosa $\left(\left(^{2}(6)=20.94, p<0.01\right)\right.$, dementia $\left(\left({ }^{2}(6)=14.07, p<\right.\right.$ $0.05)$ and broken arm $\left(\left(^{2}(6)=15.40, p<0.05\right)\right.$, but not for chicken pox or asthma (see Table 5). For depression, young children were more likely to choose 'less than 1 month' compared to middle and old children, who were more likely to choose ' 1 month to 6 months' as a recovery time compared to young children. For anorexia nervosa, young children were more likely to choose 'less than 1 month' compared to old children, whereas old children were more likely to choose 'more than 1 year' compared to both young and middle children. For dementia, young children were more likely to choose 'less than 1 month', ' 1 month to 6 months' and ' 6 months to 1 year' than old children, whereas old children were more likely to choose 'never' compared to young and middle children. For broken arm, old children were more likely to choose ' 6 months to 1 year' than young children. The frequencies indicated that, for chicken pox, the majority of children tended to respond that the principal character would recover in less than 1 month, and for asthma, never.

\section{The coherence of children's causal-explanatory frameworks}

CFA was again employed to examine the causal-explanatory frameworks (i.e., the consequence-curability/timeline links) which underlay the children's responses, and to ascertain the frequencies of the various 'types' (consequences-curability/timelines).

Children's consequence-curability/timeline profiles. A number of 'types' were identified, highlighting commonality in the consequences but variation in the curability/timelines chosen. For each of the mental and physical illnesses/ailments, with the exception of dementia and chicken pox, children chose the same consequence but different curability/timelines. For example, children responding to the depression vignette tended to choose the consequence 'have therapy', but curability/timelines ranged from 'less than 1 month' to ' 6 months to 1 year' (see 
Table 6 for the profiles (types) identified for each mental and physical illness/ailment diagnosis; the first number in the 'profile' column denotes the consequence and the second the curability/timeline). A hi log linear analysis found a significant association between the children's response patterns and their age for depression $\left(\left({ }^{2}(4)=14.22, p<0.01\right)\right.$ and anorexia nervosa $\left(\left({ }^{2}(4)=16.18, p<0.01\right)\right.$. For depression, young and middle children were more likely to choose profile 4, 1 (consequence: she will need to have therapy, timeline: less than 1 month) than old children, who were more likely to choose profile 4, 2 (consequence: she will need to have therapy, timeline: 1 month to 6 months) than young children. For anorexia nervosa, young children were more likely to choose profile 2, 2 (consequence: see a doctor, timeline: 1 month to 6 months) than old children.

\section{Children's responses associated with gender}

The hi log linear analyses revealed significant associations between children's responses and gender for the timeline/curability of chicken pox $\left(\left({ }^{2}(3)=13.00, p<0.01\right)\right.$ and broken arm $((2)=13.45, p<0.01)$. Post hoc chi-squared tests revealed that girls were more likely to choose 'less than 1 month' as a recovery time compared to boys for chicken pox (93\% vs. 75\% respectively; $\left({ }^{2}(1)=5.88, p<0.05\right)$ and broken arm $\left(33 \%\right.$ vs. $13 \%$ respectively; $\left(^{2}(1)=5.25, p<\right.$ 0.05), while for broken arm boys were more likely to choose 'more than 1 year' than girls (12\% vs. $2 \%$ respectively; $z(1)=1.77, p<0.05)$. Once again, there were no significant three-way associations between responses, age group and gender in the hi log linear analyses.

\section{Discussion}

The findings of Study 2 suggest that between the ages of 6 and 11, the children had developmentally consistent conceptions of the consequences and curability/timeline of physical illnesses/ailments such as chicken pox, common cold and broken arm. However, their conceptions of the consequences and curability/timeline of the mental illnesses of depression, anorexia and dementia changed within this time period. Findings also indicated coherence in children's thinking in the particular consequence-curability/timeline pairings that they produced. This was true for even the youngest children who took part, although their patterns of paired consequences-curability/timelines about the mental illnesses appeared to become more factually accurate with age. The findings also indicated that the children at all ages distinguished between acute and chronic illnesses, as they provided different recovery times for asthma (a chronic illness) from that of chicken pox (an acute illness). Finally, it should be noted that the children's responses indicated that, when reasoning about mental illnesses, the younger children tended to rely on their existing knowledge about common physical illnesses/ailments, a point which will be expanded upon in the General Discussion below.

\section{General Discussion}

The present studies addressed methodological concerns with existing work and utilised the naïve theory approach to investigate age and gender differences in 6- to 11-year-old children's thinking about mental illness, focusing in particular on the children's conceptions of the illness representation components identified by Leventhal et al. $(1980,1984)$. Overall, the two studies 
found differences associated with age in the children's conceptions of mental illness. Younger children tended to provide similar responses to the mental and physical illnesses/ailments, whereas older children did not, providing different responses to the mental vs. physical illnesses/ailments. One of the principal features which differentiated the thinking of the younger and older children about mental illness was that, with increasing age, there was a reduction in the number of children offering contagion or contamination responses for causes, and medicalised responses for consequences and curability/timelines. These differences were also reflected in the patterns of paired causes-consequences (Study 1) and consequences-curability/timelines (Study 2) produced for the mental and physical illness/ailment diagnoses. For example, younger children were more likely to choose 'she caught it' (cause) and 'see a doctor' (consequence) as a profile for dementia than older children. Older children, on the other hand, were more likely to choose, for example, 'it's to do with how she thinks and feels' (cause) and 'have therapy' (consequence) as a profile for anorexia nervosa than younger children.

These results indicate that the children held coherent causal-explanatory conceptions of both mental and physical illnesses at all ages, but that the factual accuracy of their thinking about the mental illnesses improved with age, and that explanations for mental illnesses became increasingly differentiated from explanations for physical illnesses/ailments with age. That is not to say that at age 11 the children's conceptions had reached ceiling level. Their knowledge may still undergo further development after this age. Nevertheless, mental illness appears to emerge as an ontologically distinct conceptual domain by the end of middle childhood, in which mental illness is no longer conceptualised in the same kind of medicalised way as physical illness.

Furthermore, it is notable that the children exhibited a considerable degree of consensus and commonality in their conceptions of physical illness, as only a small number of profiles emerged for such illnesses in the CFAs. No significant association of response pattern with age for any of the physical illnesses/ailments was found, further supporting the view that children's representations of these physical illnesses/ailments are already formed in early childhood. In comparison, the children in both studies produced a greater number of profiles for the mental illnesses, indicating less consensus in their thinking about mental as opposed to physical illness. Furthermore, there was a lower level of consensus in the responses of the older children to the consequences component compared to the other components. This was also evident in the variation of children's responses to the consequences component across both studies. This is perhaps not surprising, as consequences are more varied and open-ended in nature. For example, if an individual developed a common cold, there would be little debate that the person had caught the illness and would recover in a very short period of time; however, in terms of the consequences of having a cold, more than one possibility arises (e.g., the individual may stay at home, or may go to see their doctor, etc.). These findings are consistent with previous research that has suggested that children's thinking about more complex and abstract aspects of illness, such as consequences or prevention, develop more slowly than their thinking about more concrete aspects such as cause or symptoms (Paterson et al., 1999). Nevertheless, even these more varied patterns were internally coherent, even in the younger children.

Children gain information about common physical ailments such as common colds, chicken pox and influenza early on in their development, and it seems likely that this is their most extensive exposure to information about illness (Lau \& Harman, 1983). Children's early illness experience is likely to inform them that illnesses are contagious, cured by the medical profession, and are relatively short-lived. This may lead them to regard newly encountered types of illness such as mental illness - as infectious and readily transmittable, treated through medical 
intervention with a short recovery period (cf. Brown, Nassau, \& Barone, 1990; Kister \& Patterson, 1980).

The older children, however, held different conceptions of the causes, consequences, curability and timeline of the mental vs. the physical illness/ailment diagnoses. They did not make predictions about mental illness based on what they knew about common physical ailments. They appeared to believe that causation is not necessarily a result of contagion or contamination, but may result from internal as well as external agents. Hence, the older children in Study 1 included psychological factors as potential causes of the mental illnesses, suggesting a belief that the mind can affect how a person feels, and that there is an interaction between mind and body. This was also true for the consequences of the mental illness diagnoses. The responses provided by the older children in Study 1 and Study 2 suggested that they were no longer relying on a medical model to explain the causes, consequences, curability and timeline of the mental illnesses presented. These findings suggest that it is during the course of middle childhood that the mental illness domain becomes differentiated from the physical illness/ailment domain.

Although the errors that the younger children were making may have been based on their own experience, they demonstrated conceptions of physical ailments which they may not have directly experienced themselves, for example asthma and broken arms. Wider exposure to information about physical conditions through experiences of friends or family members, or open discussion at school, may well have impacted on their conceptions of these illnesses. Mental illness may be equally well understood if openly discussed within the school environment using age-appropriate terminology and methods such as storybooks. This may aid in combating the negative and rejecting response found in children by previous work towards the mentally ill (e.g., Poster et al., 1986; Weiss, 1986; 1994; Wilkins \& Velicer, 1980).

Although the two studies found clear differences associated with age in children's conceptions of the causes, consequences, curability and timeline of the mental illnesses, very few differences were found in the children's responses associated with gender. Where gender differences were found, girls tended to provide responses of a more caring and compassionate nature. Hence, in Study 1, for the consequences of depression, girls were more likely than boys to choose the consequence 'she will need help and support from her relatives'. This supports the findings of previous work (Ross \& Ashok, 1983) that girls show greater compassion towards mental illness compared to boys. However, relatively few gender differences were found (and there were no interactions between age and gender in the data either), so gender does not appear to play an especially significant role within this domain.

There are some limitations of the present studies. First, the majority of children who participated in the research were English, white and from middle class backgrounds. These characteristics may limit the generalisability of the results to other populations. Second, the research only presented children with descriptions of adult female principal characters in the vignettes. Future studies should explore the conceptions of mental illness held by children from other social class backgrounds and other national-cultural backgrounds, and should investigate children's conceptions of mental illness in characters with different characteristics, for example 'adult male' or 'child'. Furthermore, future research needs to examine the factors that might influence the development of children's conceptions of mental illness, for example parental knowledge of and attitudes to mental health problems, and exposure to issues relating to mental illness at school and in the mass media, to further aid the development of age-appropriate stigma reduction programmes.

To conclude, the studies reported in this paper have both theoretical and applied 
implications. They demonstrate the usefulness of the Leventhal model in the investigation of children's conceptions of mental illness. They revealed evidence of developmental trends in children's thinking about the causes, consequences, curability and timeline of mental illness, whereby younger children tend to rely on a 'medical model' when reasoning about the novel mental illnesses, while older children do not. However, at all ages, the children demonstrated causal-explanatory understandings of the causes, consequences, curability and timeline of mental as well as physical illnesses, and were coherent in the responses that they gave. The older children provided evidence that mental and physical illnesses are ontologically distinct conceptual domains by the end of middle childhood. On a more applied note, the language that is used to communicate with children of primary school age in relation to mental illness may be important for fostering their understanding. In adopting age-appropriate terminology, the present research has not only overcome a methodological problem of previous studies, but has also helped to identify a comprehensible language which may be used to communicate with children about mental illness in an age-appropriate way in stigma reduction programmes. 


\section{References}

American Psychiatric Association. (1995). Diagnostic and statistical manual of mental disorders (4th ed.): International version. Washington, DC: Author.

Appleby, L., \& Wessely, S. (1988). Public attitudes to mental illness: The influence of the Hungerford massacre. Medicine, Science and the Law, 28 (4), 291-295.

Bibace, R., \& Walsh, M. (1980). Development of children's concepts of illness. Pediatrics, 66, 912-917.

Borinstein, A. (1992). Public attitudes towards persons with mental illness. Health Affairs, 11 (3), 186-196.

Brockman, J., \& D'Arcy, C. (1978). Correlates of attitudinal social distance toward the mentally ill: A review and re-survey. Social Psychiatry, 13, 69-77.

Brown, L., Nassau, J., \& Barone, V. (1990). Differences in AIDS knowledge and attitudes by grade level. Journal of School Health, 60, 270-275.

Buchanan-Barrow, E., Bati, M., \& Barrett, M. (2003). Children's understanding of illness: The generalisations of illness according to exemplar. Journal of Health Psychology, 8 (6), 659670 .

Buchanan-Barrow, E., Bati, M. \& Barrett, M. (2004). Healthy and chronically ill children's generalisation of illness to biological and non-biological categories. Infant and Child Development, 13 (5), 435-450.

Chi, M., \& Ceci, S. (1987). Content knowledge: Its role, representation and restructuring in memory development. In H. Reese (Ed.), Advances in child development and behaviour (vol 20, pp. 91-142). New York: Academic Press.

Coie, J., \& Pennington, B. (1976). Children's perceptions of deviance and disorder. Child Development, 47, 407-413.

Conant, S., \& Budoff, M. (1983). Patterns of awareness in children's understanding of disabilities. Mental Retardation, 21, 119-125.

de Rosa, A. (1987). The social representations of mental illness in children and adults. In S. Moscovici \& W. Doise (Eds.) Current issues in European social psychology (vol 2, pp. 47138). New York: Cambridge University Press.

Dollinger, S., Thelen, M., \& Walsh, M. (1980). Children's conceptions of psychological problems. Journal of Clinical Child Psychology, 9, 191-194.

Fox, C. (2005). Children's representations of mental illness. Unpublished PhD Thesis. University of Surrey, Guildford.

Goldman, S., Whithney-Saltiel, D., Granger, J., \& Robin, J. (1991). Children's representations of 'everyday' aspects of health and illness. Journal of Paediatric Medicine, 16, 747-766.

Hall, P., Brockington, I., Levings, J., \& Murphy, C. (1993). A comparison of responses to the mentally ill in two communities. British Journal of Psychiatry, 162, 99-108.

Hergenrather, J., \& Rabinowitz, M. (1991). Age-related differences in the organisation of children's knowledge of illness. Developmental Psychology, 27, 952-959.

Inagaki, K. (1997, April). Endogenous variables mediating disease transmission. Paper presented at the Biennial meeting of the Society for Research in Child Development, Washington D.C., USA.

Kalish, C. (1997). Children's understanding of mental and bodily reactions to contamination: What you don't know can hurt you but cannot sadden you. Developmental Psychology, 33, 79-91. 
Kister, M., \& Patterson, C. (1980). Children's conceptions of the causes of illness: Understanding of contagion and use of immanent justice. Child Development, 51, 839-846.

Lau, R., \& Hartman, K. (1983). Common sense representations of common illnesses. Health Psychology, 2, 167-185.

Leventhal, H., Meyer, D., \& Nerenz, D. (1980). The Common sense representation of illness danger. In S. Rachman (Ed.), Medical psychology, (vol 2, pp. 7-30). New York: Pergamon.

Leventhal, H., Nerenz, D., \& Steele, D. (1984). Illness representations and coping with health threats. In A. Baum \& J. Dinger (Eds.) Handbook of psychology and health, (vol 4, pp. 221-252). New York: Erlbaum.

Levey, S., \& Howells, K. (1994). Accounting for the fear of schizophrenia. Journal of Community \& Applied Social Psychology, 4, 313-328.

Link, B., \& Cullen, F. (1986). Contact with the mentally ill and perceptions of how dangerous they are. Journal of Health and Social Behaviour, 27 (4), 289-302.

Marsden, G., \& Kalter, N. (1976). Children's understanding of their emotionally disturbed peers; I the concept of emotional disturbance. Psychiatry, 39, 227-238.

Novak, D. (1974). Children's reactions to emotional disturbance in imaginary peers. Journal of Consulting and Clinical Psychology, 42, 462.

Nunnally, J. (1961). Popular conceptions of mental health. New York: Holt, Reinhart and Winston.

Paterson, J., Moss-Morris, R., \& Butler, S. (1999). The effect of illness experience and demographic factors on children's illness representations. Psychology and Health, 14, 117-129.

Perrin, E., \& Gerrity, P. (1981). There's a demon in your belly: Children's understanding of illness. Pediatrics, 67, 841-849.

Poster, E., Betz, C., Mckenna, A., \& Mossar, M. (1986). Children's attitudes towards the mentally ill as reflected in human figure drawings and stories. Journal of the American Academy of Child Psychiatry, 25, 680-686.

Rabkin, J. (1974). Public attitudes toward mental illness: A review of the literature. Schizophrenia Bulletin, 10, 9-33.

Raman, L. \& Gelman, S. (2007). Children's recognition of time in the causes and cures of physical and emotional reactions to illnesses and injuries. British Journal of Psychology, 98, 389410.

Ross, N., \& Ashok, M. (1983). Adolescents' attitudes towards mental illness: Relationship between components and sex differences. Social Psychiatry, 18, 45-50.

Royal College of Psychiatrists (1998-2003). Stigma campaign. London: Royal College of Psychiatrists.

Royal, G., \& Roberts, M. (1987). Students' perceptions of and attitudes toward disabilities: A comparison of twenty conditions. Journal of Clinical Child Psychology, 16, 122132.

Siegal, M. (1988). Children's knowledge of contagion and contamination as causes of illness. Child Development, 59, 1353-1359.

Siegal, M., \& Peterson, C. (1999). Children's understanding of biology and health. Cambridge: Cambridge University Press.

Sigelman, C., Maddock, A., Epstein, J., \& Carpenter, W. (1993). Age differences in understandings of disease causality: AIDS, colds and cancer. Child Development, 64, 272-284.

Spitzer, A., \& Cameron, C. (1995). School-age children's perceptions of mental illness. 
Western Journal of Nursing Research, 17(4), 398-415.

Tabachnick, B.G. \& Fidell, L.S. (2006). Using Multivariate Statistics. New York, NY, US: HarperCollins

Trute, B., Tefft, B., \& Segall, A. (1989). Social rejection of the mentally ill: A replication study of public attitude. Social Psychiatry and Psychiatric Epidemiology, 24, 69-76.

von-Eye, A. (1990). Introduction to configural frequency Analysis: The search for types and anti-types in cross-classifications. New York, NY, US: Cambridge University Press.

Wahl, O. (2002). Children's views of mental illness: A review of the literature. Psychiatric Rehabilitation Skills, 6, 134-158.

Weiss, M. (1985). Children's attitudes towards mental illness as assessed by the Opinions about Mental Illness Scale. Psychological Reports, 57, 251-258.

Weiss, M. (1986). Children's attitudes toward the mentally ill: A developmental analysis. Psychological Reports, 58, 11-20.

Weiss, M. (1994). Children's attitudes toward the mentally ill: An eight-year longitudinal follow-up. Psychological Reports, 74, 51-56.

Wellman, H. (1990). The child's theory of mind. Cambridge, MA: MIT Press.

Wellman, H., \& Gelman, S. A. (1992). Cognitive development: Foundational theories of core domains. Annual Review of Psychology, 43, 337-375.

Wellman, H., \& Gelman, S. A. (1998). Knowledge acquisition in foundational domains. In W. Damon (Ed.), Handbook of child psychology, vol. 2: Cognition, perception and language (pp. 523-573). New York, US: John Wiley \& Sons.

Wilkins, J. \& Velicer, W. (1980). A semantic differential investigation of children's attitudes toward three stigmatized groups. Psychology in Schools, 17, 364-371. 
Table 1: Study 1: Cause of the mental illness analysed by age group

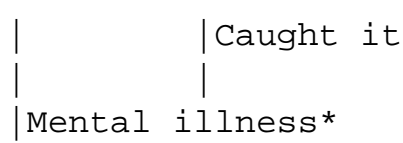

|Nasty to friend |Ate something

| DPa

Thinks and feels $\mid \begin{aligned} & \text { Someth } \\ & \mid \text { with b }\end{aligned}$ 
Table 2: Study 1: Consequence of the mental illness analysed by age group

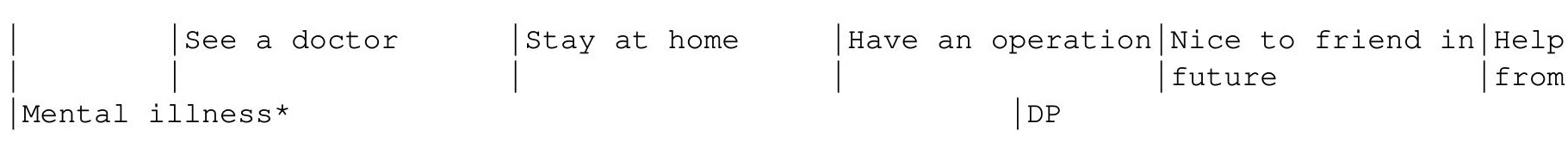


Table 3: Study 1: Profiles identified for each of the mental and physical illnesses/ailments

\begin{tabular}{|c|c|c|c|c|c|}
\hline $\begin{array}{l}\text { Illness } \\
\text { a }\end{array}$ & Profile & Cause & Consequence & $\mathrm{N}$ & Z \\
\hline \multirow[t]{4}{*}{ DP } & 3,4 & Nasty to her friend & $\begin{array}{l}\text { Nice to her } \\
\text { friend }\end{array}$ & 12 & $4.68 \star$ \\
\hline & 4,1 & Thinks and feels & See a doctor & 12 & $4.68 *$ \\
\hline & 4,5 & Thinks and feels & Help and support & 38 & $18.80 *$ \\
\hline & 4,6 & Thinks and feels & Have therapy & 19 & $8.48 *$ \\
\hline \multirow[t]{6}{*}{ AN } & 2,1 & She ate $s^{\prime}$ thing bad & See a doctor & 9 & $3.05 *$ \\
\hline & 2,3 & She ate $s^{\prime}$ thing bad & Have operation & 9 & $3.05 *$ \\
\hline & 4,1 & Thinks and feels & See a doctor & 24 & $11.20 *$ \\
\hline & 4,3 & Thinks and feels & Have operation & 18 & $7.94 \star$ \\
\hline & 4,5 & Thinks and feels & Help and support & 9 & $3.05 *$ \\
\hline & 4,6 & Thinks and feels & Have therapy & 12 & $4.68 *$ \\
\hline \multirow[t]{5}{*}{$\mathrm{DM}$} & 1,1 & She caught it & See a doctor & 9 & $3.05 *$ \\
\hline & 5,1 & $\begin{array}{l}\text { S'thing wrong } \\
\text { w/brain }\end{array}$ & See a doctor & 19 & $8.48 *$ \\
\hline & 5,3 & $\begin{array}{l}\text { S'thing wrong } \\
\text { w/brain }\end{array}$ & Have operation & 28 & $13.37 *$ \\
\hline & 5,5 & $\begin{array}{l}\text { S'thing wrong } \\
\text { w/brain }\end{array}$ & Help and support & 25 & $11.74 *$ \\
\hline & 5,6 & $\begin{array}{l}\text { S'thing wrong } \\
\text { w/brain }\end{array}$ & Have therapy & 13 & $5.22 \star$ \\
\hline
\end{tabular}

Table continues on next page $/ \ldots$ 


\begin{tabular}{|c|c|c|c|c|c|}
\hline \multirow[t]{3}{*}{$\mathrm{BA}$} & 6,1 & She fell off bike & See a doctor & 55 & $26.95 *$ \\
\hline & 6,2 & She fell off bike & Stay at home & 15 & $5.22 \star$ \\
\hline & 6,3 & She fell off bike & Have operation & 46 & $23.15 *$ \\
\hline \multirow[t]{2}{*}{$\mathrm{CP}$} & 1,1 & She caught it & See a doctor & 68 & $32.92 *$ \\
\hline & 1,2 & She caught it & Stay at home & 36 & $24.78 *$ \\
\hline \multirow[t]{2}{*}{$\mathrm{C}$} & 1,1 & She caught it & See a doctor & 64 & $35.10 *$ \\
\hline & 1,2 & She caught it & Stay at home & 49 & $17.72 *$ \\
\hline
\end{tabular}

aDP = Depression, $\mathrm{AN}=$ Anorexia Nervosa, $\mathrm{DM}=$ Dementia, $\mathrm{BA}=$ Broken Arm, $\mathrm{CP}=$ Chicken Pox, $\mathrm{C}=\mathrm{Cold}$ *Significant at Bonferroni-adjusted alpha of 0.0014 
Table 4: Study 2: Consequence of the mental illness analysed by age group

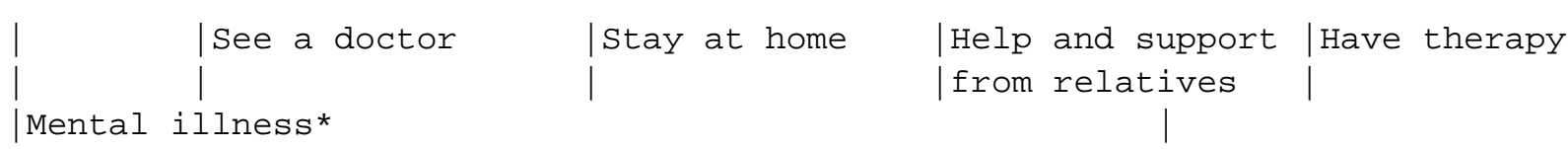


Table 5: Study 2: Curability/timeline of the mental illness analysed by age group

\begin{tabular}{|c|c|c|c|c|}
\hline & Less than 1 month & $\begin{array}{l}1 \text { month to } 6 \\
\text { months }\end{array}$ & $\mid 6$ months to 1 year $\mid$ & |More than 1 year \\
\hline Mental & llness * & & $\mathrm{DPa}$ & \\
\hline
\end{tabular}


Table 6: Study 2: Profiles identified for each of the mental and physical illnesses/ailments

\begin{tabular}{|c|c|c|c|c|c|}
\hline Illnessa & Profile & Consequence & Curability/Timeline| & $\mathrm{N}$ & $\mathrm{Z}$ \\
\hline \multirow[t]{3}{*}{ DP } & 4,1 & Have therapy & Less than 1 month & 14 & $3.34 \star$ \\
\hline & 4,2 & Have therapy & 1 month to 6 months & 18 & $4.98 *$ \\
\hline & 4,3 & Have therapy & 6 months to 1 year & 18 & $4.98 *$ \\
\hline \multirow[t]{3}{*}{ AN } & 2,2 & See a doctor & 1 month to 6 months & 14 & $3.34 *$ \\
\hline & 2,3 & See a doctor & 6 months to 1 year & 17 & $4.57 \star$ \\
\hline & 2,4 & See a doctor & More than 1 year & 14 & $3.34 *$ \\
\hline \multirow[t]{2}{*}{ DM } & 1,5 & $\begin{array}{l}\text { Help and } \\
\text { Support }\end{array}$ & Never & 26 & $8.28 *$ \\
\hline & 2,4 & See a doctor & More than 1 year & 14 & $3.34 *$ \\
\hline \multirow[t]{2}{*}{$\mathrm{CP}$} & 2,1 & See a doctor & Less than 1 month & 64 & $23.92 *$ \\
\hline & 3,1 & Stay at home & Less than 1 month & 32 & $10.75 *$ \\
\hline \multirow[t]{3}{*}{$\mathrm{BA}$} & 2,1 & See a doctor & Less than 1 month & 20 & $5.80 *$ \\
\hline & 2,2 & See a doctor & 1 month to 6 months & 56 & $20.63 *$ \\
\hline & 2,3 & See a doctor & 6 months to 1 year & 14 & $3.34 \star$ \\
\hline \multirow[t]{2}{*}{ A } & 2,4 & See a doctor & More than 1 year & 23 & $7.04 \star$ \\
\hline & 2,5 & See a doctor & Never & 43 & $15.27 \star$ \\
\hline
\end{tabular}

${ }^{\mathrm{a}} \mathrm{DP}=$ Depression, $\mathrm{AN}=$ Anorexia Nervosa, $\mathrm{DM}=$ Dementia, $\mathrm{CP}=$ Chicken Pox, $\mathrm{BA}=$ Broken Arm, $\mathrm{A}=$ Asthma * Significant at Bonferroni-adjusted alpha of 0.0025 


\section{Appendix 1: Vignettes presented to children}

|Depression:

|This is about a woman called* ..... She has got Depression. This means that she feels sad all of the time and doesn't like to do the things that she usually does anymore. She feels as if she has no energy and feels tired most of the time. In general she thinks badly of herself and feels that she isn't worth anything and blames herself when things go wrong. She also finds it hard to sleep.

Anorexia Nervosa:

This is about a woman called* ..... She has got Anorexia Nervosa. This means that she has lost a lot of weight and because of this her life is now in danger. She is frightened of putting on weight and even though she is very thin, she still says that she is fat and needs to lose more weight.

|Dementia (Alzheimer's Type):

This is about a woman called* ..... She has got Dementia. This means that she finds it hard to remember things and to learn new |information. She finds it hard to get herself washed and dressed| |in the morning and also needs help to eat, so someone has to feed| her. She doesn't recognise her family anymore and needs to be looked after all the time.

Chicken Pox:

|This is about a woman called* ..... She has got Chicken Pox. This means that she doesn't feel very well and isn't very hungry. She| is covered in a rash of red spots that have got crusts that will drop off. The rash is very itchy so she has to try not to scratch the spots.

Broken Arm:

This is about a woman called* ..... She has broken her arm. This means that her arm is swollen and bruised and it really hurts when she tries to wiggle her fingers.

Common cold:

This is about a woman called* ..... She has got a cold. This means that she has a runny nose, a headache and a sore throat. She feels chilly but she has a temperature and she has a cough. |Causes Embedded in Vignettes in Study 2:

Depression: Her depression is caused by how she thinks and feels.|

Anorexia Nervosa: Her anorexia is caused by how she thinks and feels.

Dementia (Alzheimer's Type): She has dementia because there is something wrong with her brain.

|Chicken Pox: She got chicken pox because she caught it from her sister.

Broken Arm: She broke her arm when she fell off her bike.

Illness presented in Study 2 instead of common cold:

Asthma: This is about a woman called* ..... She has got asthma. She| |has had asthma all her life. This means that sometimes her chest| feels tight and she gets wheezy. When this happens she finds it hard to breathe and she coughs a lot. 
Appendix 2: Response cards presented to children

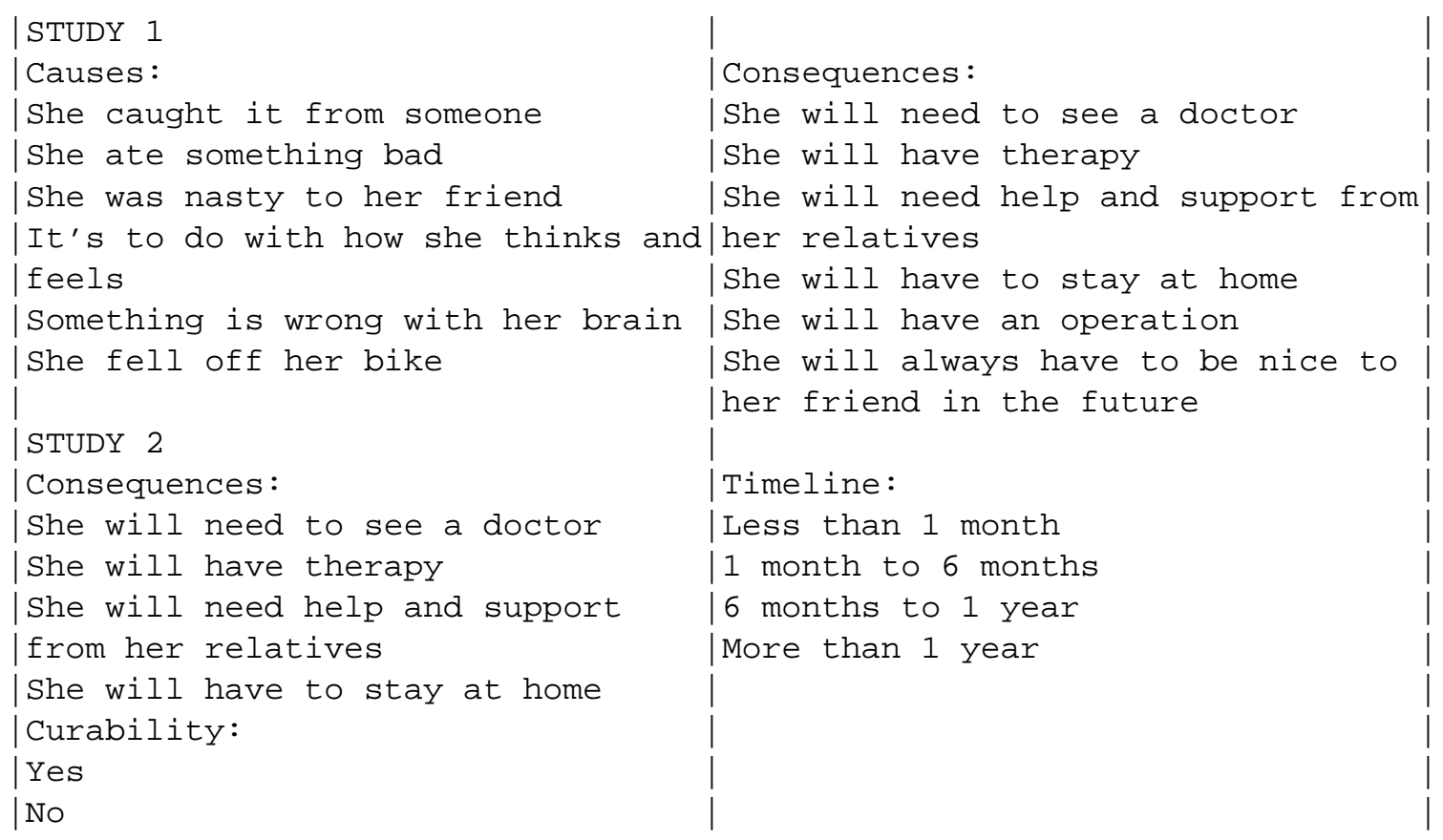

